\title{
Mental Health, Broad Autism Phenotype and Psychological Inflexibility in Mothers of Young Children with Autism Spectrum Disorder in Australia: a Cross-sectional Survey
}

This is a post-peer-review, pre-copyedit version of an article published in Autism.

The final authenticated version is available online at:

http://dx.doi.org/ 10.1177/1362361320984625

Manuscript Accepted 5 December 2020

\author{
Kavindri Kulasinghe ${ }^{1}$, Koa Whittingham ${ }^{1}$ and Amy E. Mitchell ${ }^{2}$ \\ ${ }^{1}$ Queensland Cerebral Palsy and Rehabilitation Research Centre, Faculty of Medicine, The \\ University of Queensland, Brisbane, Australia; \\ ${ }^{2}$ Parenting and Family Support Centre, School of Psychology, The University of Queensland, \\ Brisbane, Australia.
}

\section{Author Note}

This work was supported by a University of Queensland Graduate School Scholarship (KK) and a Children's Hospital Foundation Early Career Fellowship (AEM; ref. 50223). Correspondence should be addressed to Miss Kavindri Kulasinghe, Queensland Cerebral Palsy and Rehabilitation Research Centre, Centre for Children's Health Research, 62 Graham Street, South Brisbane, Queensland 4101, Australia. Email: k.kulasinghe@uq.edu.au

\section{Conflict of Interest}

The Parenting and Family Support Centre is partly funded by royalties stemming from published resources of the Triple P - Positive Parenting Program, which is developed and owned by The University of Queensland (UQ). Royalties are also distributed to the Faculty of Health and Behavioural Sciences at UQ and contributory authors of published Triple P resources. Triple P International (TPI) Pty Ltd is a private company licensed by Uniquest Pty Ltd on behalf of UQ, to publish and disseminate Triple P worldwide. The authors of this article have no share or ownership of TPI. TPI had no involvement in the writing of this article. Miss Kulasinghe, Dr Whittingham and Dr Mitchell are employees at UQ. 


\title{
Lay Abstract
}

Mothers of children with autism tend to have poorer mental health outcomes compared to most mothers. Lack of social support, parenting challenges and relationship difficulties are more common for mothers of children with autism and can all affect maternal mental health. Mothers of children with autism are also more likely to have some autistic features, called the broad autism phenotype, that can contribute to poorer mental health; however, how these factors relate to one another are unclear. This study found that mothers who were less flexible in their thinking and behaviour and had more difficult parenting experiences tended to have poorer mental health. Mothers with more autistic features were less flexible in their thinking and behaviour, which, in turn, was linked to greater symptoms of depression, anxiety and stress. Mothers with greater autistic features also reported more difficult parenting experiences, which was in turn linked with greater symptoms of anxiety and depression. This study suggests that supporting mothers of young children with autism to manage parenting challenges and become more flexible with their thinking and behaviour could help to improve their mental health.

\begin{abstract}
Mothers of children with autism spectrum disorder (ASD) are more likely to have features of the broad autism phenotype (BAP) and adverse mental health outcomes. The BAP can contribute to poorer mental health; however, the mechanism behind this relationship remains uncertain. This study investigated both the predictors of mental health and the relationship between the BAP and mental health symptoms in mothers of children with ASD. This crosssectional survey recruited 232 Australian mothers ( $\geq 18$ years) of children with ASD (0-10 years) and assessed maternal BAP, mental health, adult attachment style, degree of social support and parenting experience. Hierarchical multiple regressions, t-tests, correlations and mediation analyses were conducted. Psychological inflexibility was the greatest unique
\end{abstract}


predictor of anxious, depressive and stress symptomatology. Challenging parenting experiences predicted depressive, anxious and stress symptomatology while the BAP also uniquely predicted anxious symptoms. Both psychological inflexibility and challenging parenting experiences were significant mediators of the relationships between BAP and depressive symptoms and between BAP and anxiety. Psychological inflexibility alone mediated the relationship between BAP and stress. Targeting psychological inflexibility and supporting parenting are promising avenues for future interventions to support the mental health of mothers of young children with ASD.

Key Words: maternal mental health, autism spectrum disorder, psychological inflexibility, broad autism phenotype 


\section{Introduction}

Autism spectrum disorder (ASD) is characterised by social interaction and communication differences, as well as restrictive, repetitive and stereotypical behaviours (American Psychiatric Association, 2013). Caring for a child with ASD can have flow-on effects on parental mental health. Factors such as the stress associated with caring for a child with ASD and financial burden can affect parental mental health (Prata et al., 2019). As the typical primary caregivers of these children, mothers of children with ASD have worse mental health outcomes when compared to fathers of children with ASD, mothers of typically developing children and mothers of children with other developmental disabilities (Bitsika et al., 2013; Ingersoll et al., 2011; Keenan et al., 2016). Improving our understanding of the factors that predict maternal mental health is important. Firstly, because the mental health of mothers is an important health outcome in its own right; and secondly, because poor mental health in mothers of children with ASD can affect child developmental outcomes (BernardBonnin et al., 2004) and efficacy of parental intervention engagement and implementation (Alvarez et al., 2015).

A factor that can influence maternal mental health is the presence of the broad autism phenotype (BAP). Due to the heritable nature of ASD, mothers of children with ASD are more likely to have features of the BAP when compared to mothers of children without ASD (Ingersoll et al., 2011). The BAP is the presence of subclinical autistic features in first degree relatives of individuals with ASD, including an aloof and rigid personality as well as social communication deficits (Piven, 2001). Previous literature has identified an association between BAP and anxiety (Lau et al., 2014); however, the link between the BAP and depression is ambiguous. Some studies have reported that the BAP was associated with greater depressive symptoms (Ingersoll et al., 2011; Pruitt et al., 2016) although Piven and Palmer's earlier (1999) study found no association between features of the BAP and clinical 
depression. However, their identification of the BAP relied on a validated algorithm based on results of a personality assessment, psychiatric interview and friendship assessment (Piven et al., 1997) whereas Ingersoll et al. (2011) and Pruitt et al. (2016) used single self-report measures of the BAP, making comparison between studies difficult. Research into the mental health of mothers of children with ASD needs to take maternal BAP into account.

There are similarities between the rigidity and cognitive inflexibility typical of individuals with the BAP and the construct of psychological inflexibility, which involves the domination of cognitive processes over present-moment contextual factors and includes both behavioural rigidity and perspective taking deficits (Hayes et al., 2011). For example, an individual who is psychologically inflexible may have difficulties remaining psychologically present in the moment, instead of being with the past or future, resulting in rumination and poor mental health (Hayes et al., 2011). In the parenting context, psychological inflexibility may contribute to problems adapting flexibly to children's needs, taking children's perspectives, and balancing competing needs and desires. Psychological inflexibility predicts symptoms of depression, anxiety and stress in mothers of children with chronic health and developmental diagnoses including autism (Sairanen et al., 2018), mothers of children with cerebral palsy (Whittingham et al., 2013), and parents of children undergoing cancer treatment (Cernvall et al., 2016); psychological distress in parents of children with acquired brain injury (Brown, Whittingham, \& Sofronoff, 2015); and bonding in parents of preterm infants (Evans et al., 2012). Targeting psychological flexibility is effective in improving psychological outcomes (Blackledge \& Hayes, 2006; Joekar et al., 2016; Lunsky et al., 2018) and also extends to improving maternal and family well-being (Leeming \& Hayes, 2016), disagreements between parents and parenting confidence (Brown, Whittingham, Boyd, et al., 2015). 
Parenting a child with ASD, regardless of whether or not the parent has BAP, can also can raise unique parenting challenges that may contribute to maternal distress, including challenges related directly to managing the child's ASD symptomatology and behavioural characteristics, and parent characteristics including parental perception of child disability and parenting confidence (Mak et al., 2007; Miranda et al., 2019). Autistic mothers are more likely experience perinatal depression, isolation, anxiety and difficulty with parenting when compared to mothers without autism (Pohl et al., 2020).

Maternal mental health may also be affected by the social difficulties associated with the BAP, which can affect social relationships and romantic relationship satisfaction (Pruitt et al., 2016). Social support, particularly informal social support from family and friends, has been linked to improved mental health in mothers of children with ASD (Benson, 2006; Benson \& Karlof, 2009; Boyd, 2002). Parents with higher BAP scores have previously reported less social support, possibly due to difficulties with interpersonal communication (Ingersoll \& Hambrick, 2011). Importantly, social support appears to mediate the relationship between the BAP and depression and stress (Ingersoll \& Hambrick, 2011). Pruitt et al. (2016) further found that romantic relationship satisfaction, rather than perceived support from family and friends, mediated the relationship between the BAP and maternal mental health. However, their study only included mothers in romantic relationships; and the role of broader social support for mothers of children with ASD, regardless of relationship status, is yet to be explored.

Insecure attachment styles can also impact on ability to access social support and are risk factors for adverse mental health outcomes, with anxious and avoidant adult attachment associated with anxiety, depression and stress in neurotypical individuals (Cantazaro \& Wei, 2010; Mikulincer \& Shaver, 2012). Moreover, adult avoidant and anxious attachment was associated with the BAP in undergraduate university students, likely due to social 
communication difficulties affecting their ability to create and maintain social relationships, with these negative experiences, in turn, affecting attachment styles (Lamport \& Turner, 2014). Negative childhood experiences such as bullying, which is more prevalent among individuals with autistic traits, may affect attachment style (Cappadocia et al., 2012; Little, 2002). Past bullying experiences were found to mediate the relationship between autistic traits and mental health in undergraduate students (Rosbrook \& Whittingham, 2010). Similarly, recalled childhood teasing is correlated with anxious adult attachment styles (Ledley et al., 2006). Whether adult attachment style mediates the relationship between BAP and mental health in mothers of children with ASD is yet unknown.

Overall, the relationship between the BAP and mental health in mothers of children with ASD remains unclear, with the contributions of psychological inflexibility and adult attachment style largely unexplored. Likewise, the effects of social support and parenting experience on maternal mental health, in the context of BAP and psychological inflexibility, need to be further elucidated. Therefore, this study aimed to identify correlational relationships between the mental health of mothers of children with ASD and their psychological inflexibility, degree of social support, adult attachment style and parenting experience. Mediators of the relationship between the BAP and maternal mental health were also explored.

\section{Methods}

This cross-sectional, online survey was developed using Qualtrics software and was made available online to mothers of children with ASD from October 2019 to January 2020. The survey consisted of 72 questions, which took mothers an average of 41.5 minutes to complete. Mothers were recruited via study information distributed Australia-wide to ASD family support groups, autism schools and primary healthcare networks, and via social media 
platforms, word-of-mouth and newsletters. These broad recruitment strategies were used in an attempt to reduce selection bias and gain a representative sample with diverse socioeconomic and cultural backgrounds. No incentives were offered for participation. Community members were not involved in the design of the survey. The STROBE crosssectional reporting guidelines were used (von Elm et al., 2008).

\section{Procedures}

Ethical approval was granted by The University of Queensland Human Research Ethics Committee (2019002138). Participants met the following inclusion criteria: 1) were aged 18 years or older, 2) were mothers of one or more children aged up to 10 years who had been diagnosed with ASD, 3) could read and understand English and 4) resided in Australia. Due to the anonymous nature of the survey, ASD diagnosis was determined via parental endorsement. There were no exclusion criteria. Interested participants accessed online study information and consented before the survey.

\section{Measures}

\section{Demographic Questionnaire}

A modified version of the Family Background Questionnaire (Morawska \& Sanders, 2010) was used to collect demographic information including parent age, cultural background, relationship status, number of children, socioeconomic status and education. Respondents were asked to report on whether their child received any interventions, supports, programs or therapies for their Autism Spectrum Disorder. Mothers were asked whether they had a diagnosis of ASD or self-identified as having ASD.

\section{Depression, Anxiety and Stress Scale (DASS-21)}

The DASS-21 is a 21-item questionnaire assessing symptoms of depression, anxiety and stress in adults (Lovibond \& Lovibond, 1995). Participants rate items on a 4-point Likert scale reflecting how much the statement applied to them in the past week (Lovibond \& 
Lovibond, 1995). In this sample, the internal consistency for the three subscales were high ( $\alpha=0.94$ whole scale; 0.91 Depression subscale; 0.84 Anxiety subscale; 0.87 Stress subscale).

\section{The Acceptance and Action Questionnaire (AAQ-II)}

The AAQ-II is a measure of psychological inflexibility consisting of 7 items that are rated on a 7-point Likert scale ranging from 1 (never true) to 7 (always true), where lower scores indicate lower levels of psychological inflexibility (Bond et al., 2011). The AAQ-II showed excellent internal consistency $(\alpha=0.91)$ in this sample.

\section{The Broad Autism Phenotype Questionnaire (BAPQ)}

The BAPQ contains 36 items that assess features of ASD in adults (Hurley et al., 2007; Sasson, Lam, Childress, et al., 2013). Respondents rate how much each item applies to them on a 6-point Likert scale ranging from 1 (very rarely applies) to 6 (applies very often) (Hurley et al., 2007). The subscales are based on typical features of the BAP and include Aloofness $(\alpha=0.85)$, Pragmatic Language Deficits $(\alpha=0.87)$, and the Rigid Personality subscale $(\alpha=0.92)$. The internal consistency of the total score for this sample was excellent $(\alpha=0.96)$.

\section{Autism Family Experience Questionnaire (AFEQ)}

The AFEQ is a 48-item questionnaire that measures the experiences of parents of children with ASD by exploring parental confidence, parent self-efficacy, ASD symptomatology, child behavioural problems and broader behaviours across four domains: Experience of Being a Parent of a Child with ASD (e.g. My child is getting the right help), Family Life (e.g. Family life is calm), Child Development, Understanding and Social Relationships (e.g. I know when my child feels poorly) and Child Symptomatology (e.g. My child is happy) (Leadbitter et al., 2018). Participants rate items on a 5-point Likert scale, reflecting how often the statements applied to them from 1 (always) to 5 (never) (Leadbitter 
et al., 2018). A higher score reflects more challenging parenting experiences. The AFEQ has excellent reliability in this sample for Parenting Experience $(\alpha=.87)$, Child Development $(\alpha=.81)$, Child Symptoms $(\alpha=0.85)$, Family Life $(\alpha=0.75)$, and total $(\alpha=0.93)$ scores.

\section{The Experience in Close Relationships-Revised (ECR-R) Questionnaire}

The ECR-R is a 36-item questionnaire measuring adult romantic attachment styles (Fraley et al., 2000). Respondents rate each item using a 7-point Likert scale that ranges from 1 (disagree strongly) to 7 (agree strongly) (Fraley et al., 2000). The Anxiety and Avoidance subscales (18 items each) had high internal consistencies of $\alpha=0.94$ and $\alpha=0.96$ respectively in this sample. Respondents that score higher on the anxious subscale are more likely to fear abandonment and rejection (Fraley et al., 2000). Respondents that score higher on the avoidant subscale tend to find intimacy uncomfortable and seek independence (Fraley et al., 2000).

\section{The Multidimensional Scale of Perceived Social Support (MSPSS)}

Social support was measured using the MSPSS, a 12-item, three subscale questionnaire that measures the degree of perceived social support from various sources (Pruitt et al., 2016). Each item is rated on a 7-point Likert scale ranging from 1 (very strongly disagree) to 7 (very strongly agree) (Pruitt et al., 2016). Lower scores indicate a lower degree of perceived social support. The MSPSS scale had good internal consistency for the Friends ( $\alpha=0.94)$, Family $(\alpha=0.93)$, Significant Other $(\alpha=0.93)$ and total $(\alpha=0.91)$ scales.

\section{Statistical Analysis}

Statistical analysis of data was performed using SPSS Statistical Software Version 25. Missing data at the item-level were handled according to published protocols (e.g. DASS-21) or, where no protocol was available, by pro-rating items if less than $25 \%$ of item-level responses were missing. Pairwise deletion was used to manage entirely missing data. A pvalue significance level cut-off of $<0.05$ was used to reject the null hypothesis for all 
analyses. Demographic data were analysed through descriptive statistics. Pearson correlations were used to test relationships between the BAP, social support, attachment styles, psychological inflexibility, maternal mental health and parenting experiences. Hierarchical multiple regressions were conducted to determine whether psychological inflexibility, BAP, parenting experience, adult attachment style and social support explained significant amounts of variation in maternal depressive symptoms, anxiety and stress. Relationship status was not included as a predictor as it was not significantly correlated with maternal mental health in this sample. For each model, in order to control for background variables, demographic variables (mother age, child age, mother education and financial hardship) were entered in the first block; to account for unchangeable BAP characteristics, BAP was entered in step 2; to assess independent contribution to the model, attachment variables were entered in step 3; family and support variables were entered in step 4, as these characteristics are a part of the parents' social ecological system; and psychological inflexibility was entered in the final block as it is a readily modifiable psychological variable.

Bootstrapping was used to test potential mediators of the relationships between the BAP and maternal mental health. Mediation analyses were conducted according to the process proposed by Preacher and Hayes (2004) using bootstrapping based on 5000 resamples. A variable was considered to be a potential meditator if the independent variable was significantly related to the mediator and the mediator was significantly related to the dependent variable. The independent variable was not required to be significantly related to the dependent variable, as mediation can exist even when this relation is absent (Mackinnon \& Fairchild, 2009).

\section{Results}

A total of 274 respondents started the survey; however, 42 responses were removed (1 duplicate response, 1 respondent did not complete inclusion criteria questions, 10 
respondents only completed demographic information, and 30 respondents had a large amount degree of missing data from the BAPQ, DASS and AAQ measures), resulting in a final sample of 232 participants. There were no significant differences in demographic variables (maternal age, child age, maternal education and financial hardship) between respondents who had a large amount of missing data and those who completed the survey and were included in the final sample. The pattern of missing data was missing at random $(0.59 \%$ missing, Little's MCAR Test Chi Square=8506, $\mathrm{p}=0.070$ ).

The mean age of participants was 39.13 years. The mean age of the child diagnosed with ASD was 6.69 years (child age ranged from 1-10 years) and most children were boys (72.61\%). Although most participants were from Queensland (57.58\%) there was a distribution amongst major cities $(66.81 \%, n=149)$, inner regional areas $(19.29 \%, n=43)$, outer regional areas $(13.00 \%, \mathrm{n}=29)$ and remote areas $(0.90 \%, \mathrm{n}=2)$. Most participants had a university degree or higher, were married or in a de facto relationship, and reported that during the past 12 months there had not been a time when their household could not meet essential expenses. See Table 1 for demographic information.

All children had a diagnosis of ASD. The majority reported their child's primary diagnosis as “ASD” (92.67\%, $\mathrm{n}=215)$, with some reporting a diagnosis of Asperger Syndrome $(6.03 \%, \mathrm{n}=14)$ or Pervasive Developmental Disorders - Not Otherwise Specified $(1.29 \%, n=3)$. The most common age at diagnosis was 3 years $(21.12 \%, n=49)$. The most common comorbidities for children included sensory disorders $(57.76 \%, \mathrm{n}=134)$, anxiety disorder $(38.36 \%, \mathrm{n}=89)$ and ADHD $(34.05 \%, \mathrm{n}=79)$. The most commonly accessed interventions were occupational therapy $(84.91 \%, n=197)$, speech therapy $(74.57 \%, n=173)$ and psychological therapy $(59.05 \%, \mathrm{n}=137 \overline{-})$.

Based on DASS-21 scores, most respondents reported moderate to extremely severe stress $(55.60 \%, \mathrm{n}=129)$. Almost half of respondents reported moderate to extremely severe 
depressive symptoms $(46.98 \%, \mathrm{n}=109)$ and moderate to extremely severe anxiety $(38.36 \%$, $n=89)$. Some mothers reported that they had a formal diagnosis of ASD $(6.5 \%, n=15)$, while more mothers reported that they definitely $(7.3 \%, \mathrm{n}=17)$ or probably $(15.9 \%, \mathrm{n}=37)$ selfidentified has having ASD. Based on BAPQ scores, the percentage of respondents scoring above the self-report cut-off values specified by Sasson, Lam, Childress, et al. (2013) was $38.36 \%(\mathrm{~N}=89)$ for the aloof subscale (cut-off=3.45), 26.72\% $(\mathrm{N}=62)$ for the rigid subscale (cut-off=3.70), 38.79\% $(\mathrm{N}=90)$ for the pragmatic language subscale (cut-off=2.94) and $42.67 \%(\mathrm{~N}=99)$ for the total scale $($ cut-off $=3.17)$. 


\section{Table 1}

Demographic Characteristics of Sample $(N=233)$

\begin{tabular}{lccc}
\hline & Variable & $M$ & $S D$ \\
\hline Mother age (years) & 39.13 & 5.35 \\
Child age (years) & 6.69 & 2.15 \\
\hline & $n$ & $\%$ \\
\hline
\end{tabular}

Child sex ${ }^{\mathrm{a}}$

Male

Female

Child diagnosis

Autism Spectrum Disorder (ASD)

Asperger disorder/syndrome

Pervasive Developmental Disorder - Not Otherwise Specified (PDD-NOS)

Age at diagnosis (years)

1

2

3

4

5

6

7

8

9

10

Marital status

Married/de facto

Divorced/separated

Single

Parental status

Biological mother

Non-Biological mother (Adoptive/Foster/Two mother family)

Parent education level

Some high school or less

Completed high school

Trade/technical college

Undergraduate degree

Postgraduate degree

Birth country ${ }^{\mathrm{b}}$

Australia

Other

Financial hardship in past 12 months $^{\mathrm{c}}$

Yes

No

Don't know

Mother has formal diagnosis of ASD

Mother self-identifies as having ASD

Definitely yes

Probably yes

Might or might not

167

72.6

63

27.4

215

90.0

14

3

6.03

1.29

1.7

18.5

21.1

17.2

18.5

9.5

5.2

5.2

2.6

0.4

1

81.5

189

12.1

6.5

15

98.7

229

1.29

3

4.3

13.4

23.7

34.1

24.6

57

81.9

190

18.1

42

37.1

86

62.5

145

0.4

6.5

15 
Probably not 19.8

Definitely not

Do not know

Mother in elevated range for Broad Autism Phenotype Traits ${ }^{\mathrm{d}}$

No

Yes

Maternal Depressive Symptoms ${ }^{\mathrm{e}}$

Normal

Mild

Moderate

25.9

Severe

9.5

Extremely severe

11.6

Maternal Anxiety Symptoms ${ }^{\mathrm{e}}$

Normal

40.5

Mild

20.7

Moderate

13.4

Severe

8.6

Extremely severe

16.4

Maternal Stress Symptoms ${ }^{\mathrm{e}}$

Normal

26.3

Mild

Moderate

Severe

21.6

Extremely Severe

12.1

Note. ${ }^{\mathrm{a}}$ Missing values $\mathrm{n}=2$. ${ }^{\mathrm{b}}$ Missing values $\mathrm{n}=18$. ${ }^{\mathrm{c}}$ During the past 12 months household

could not meet essential expenses. ${ }^{\mathrm{d}}$ Cut-off value of 3.17 on the BAPQ total score as

specified by Sasson, Lam, Childress, et al. (2013). ${ }^{e}$ Cut-off values as specified by the DASS21. 
Descriptive statistics and correlation coefficients for key variables are presented in Table 2. Most demographic variables were either not correlated or weakly correlated with outcome variables, except for financial hardship, which was moderately correlated with attachment avoidance $(r=0.29, \mathrm{p}<0.001)$, depression $(\mathrm{r}=0.31 ; \mathrm{p}<0.001)$, anxiety $(\mathrm{r}=0.29$; $\mathrm{p}<0.001)$ and parenting experience $(\mathrm{r}=0.29, \mathrm{p}<0.001)$. The remainder of the predictor variables were all moderately or strongly correlated with all of the outcome variables. There were significant correlations amongst all outcome variables, with psychological inflexibility having the greatest correlation with stress, anxiety and depressive symptoms. 
Table 2

Correlations and Descriptive Statistics for Key Variables

\begin{tabular}{|c|c|c|c|c|c|c|c|c|c|c|c|c|c|c|c|c|}
\hline Variables & 1 & 2 & 3 & 4 & 5 & 6 & 7 & 8 & 9 & 10 & 11 & 12 & 13 & Cronbach $\alpha$ & Mean & SD \\
\hline 1. Mother age (years) & & $0.26^{* * *}$ & $0.20^{* *}$ & 0.01 & -0.08 & -0.01 & -0.02 & 0.05 & 0.02 & -0.03 & -0.09 & -0.10 & -0.10 & - & 39.13 & 5.35 \\
\hline 2. Child age (years) & & & -0.03 & -0.03 & -0.07 & 0.03 & -0.08 & -0.00 & -0.05 & -0.07 & -0.08 & -0.11 & -0.22 & - & 6.68 & 2.15 \\
\hline 3. Mother education ${ }^{\mathrm{a}}$ & & & & $-0.28^{* * *}$ & $-0.16^{*}$ & $-0.14^{*}$ & $-0.14^{*}$ & $-0.17^{* *}$ & -0.07 & $-0.14^{*}$ & $-0.17^{*}$ & -0.02 & $-0.17^{*}$ & - & - & - \\
\hline 4. Financial hardship ${ }^{b}$ & & & & & -0.05 & $-0.14^{*}$ & $0.29^{* * *}$ & $0.21^{* *}$ & $0.18^{* *}$ & $0.31^{* * *}$ & $0.29^{* * *}$ & $0.15^{*}$ & $0.29^{* * *}$ & - & - & - \\
\hline 5. Broad autism phenotype ${ }^{c}$ & & & & & & $-0.18^{* *}$ & $0.30^{* * *}$ & $0.30^{* * *}$ & $0.39^{* * *}$ & $0.30^{* * *}$ & $0.33^{* * *}$ & $0.29^{* *}$ & $0.16^{*}$ & 0.96 & 3.06 & 0.84 \\
\hline 6. Social support ${ }^{\mathrm{d}}$ & & & & & & & $-0.50^{* * *}$ & $-0.40^{* * *}$ & $-0.40^{* * *}$ & $-0.33^{* * *}$ & $-0.34^{* * *}$ & $-0.43^{* * *}$ & $-0.44^{* * *}$ & 0.91 & 4.53 & 1.28 \\
\hline 7. Attachment avoidance ${ }^{\mathrm{e}}$ & & & & & & & & $0.65^{* * *}$ & $0.44^{* * *}$ & $0.35^{* * *}$ & $0.31^{* * *}$ & $0.42^{* * *}$ & $0.33^{* * *}$ & 0.96 & 3.13 & 1.31 \\
\hline 8. Attachment anxiety & & & & & & & & & $0.55^{* * *}$ & $0.44^{* * *}$ & $0.41^{* * *}$ & $0.50^{* * *}$ & $0.37^{* * *}$ & 0.94 & 3.18 & 1.28 \\
\hline 9. Psychological inflexibility ${ }^{\mathrm{f}}$ & & & & & & & & & & $0.66^{* * *}$ & $0.52^{* * *}$ & $0.69^{* * *}$ & $0.39^{* * *}$ & 0.91 & 23.55 & 8.90 \\
\hline 10. Stress $^{\mathrm{g}}$ & & & & & & & & & & & $0.65^{* * *}$ & $0.70^{* * *}$ & $0.43^{* * *}$ & 0.87 & 10.69 & 4.49 \\
\hline 11. Anxietyg & & & & & & & & & & & & $0.63^{* * *}$ & $0.40^{* * *}$ & 0.84 & 5.40 & 4.32 \\
\hline 12. Depression ${ }^{\mathrm{g}}$ & & & & & & & & & & & & & $0.45^{* * *}$ & 0.91 & 6.90 & 4.76 \\
\hline 13. Parenting experience ${ }^{\mathrm{h}}$ & & & & & & & & & & & & & & 0.93 & 146.42 & 21.35 \\
\hline
\end{tabular}

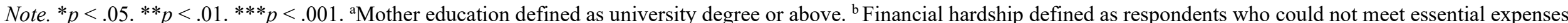

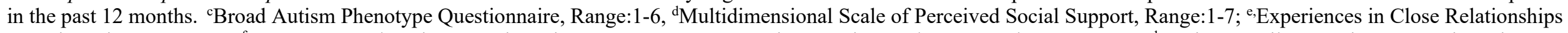
Questionnaire, Range:1-7; ${ }^{\mathrm{f}}$ Acceptance and Action Questionnaire, Range:7-49; ${ }^{\mathrm{g}}$ Depression, Anxiety and Stress Scale, Range:0-21; ${ }^{\mathrm{h}}$ Autism Family Experience Questionnaire,

Range:48-240. 


\section{Predicting Depression, Anxiety and Stress}

A series of hierarchical multiple regressions was conducted to determine which variables were significant predictors of depressive, anxious and stress symptoms in mothers of children with ASD. The assumptions of normality, linearity and homoscedasticity of the residuals were met. No outliers were found when using the Mahalanobis distance score $(\mathrm{p}<0.001)$ and Cook's scores. Tables 3-5 show the results for each step of the model.

In the model predicting depressive symptoms, demographic variables (step 1) explained a significant proportion $(10.05 \%)$ of variance, and financial hardship was the only significant predictor. Step 2 (BAP) explained an additional $8.64 \%$ of variation, and significantly improved the model; the significant predictors were financial hardship and the BAP. Step 3 (attachment variables) explained an additional $12.96 \%$ of the variation in depressive symptoms, and significantly improved the model; financial hardship, BAP and attachment anxiety made significant contributions. Parenting experience and support variables (step 4) explained an additional $7.71 \%$ of variation $(\mathrm{p}<0.001)$, and financial hardship, BAP, attachment anxiety, degree of social support and parenting experience made significant contributions to the model. Finally, psychological inflexibility (step 5) explained an additional $15.61 \%$ of the variation in depressive symptoms, and significantly improved the model. In the final model, the greatest predictors for depressive symptoms were psychological inflexibility $(\mathrm{p}<0.0001)$, financial hardship $(\mathrm{p}=0.0064)$ and parenting experience $(\mathrm{p}=0.0339)$, which accounted for $15.61 \%, 1.59 \%$ and $0.95 \%$ of unique variance in depressive symptoms, respectively.

In the model predicting anxiety, step 1 (demographics) explained a significant proportion (10.14\%) of variation, and financial hardship made a significant contribution to the model. Step 2 (BAP) explained an additional 10.91\% of the variation, which significantly improved the model. Significant predictors were financial hardship and the BAP. The 
attachment variables explained an additional $5.52 \%$ of the variation in anxiety $(\mathrm{p}<0.001)$ and the significant predictors were financial hardship, BAP and adult attachment anxiety. Step 4 (parenting experience and support variables) made a significant contribution to the model, explaining an additional $5.93 \%$ of the variation in anxiety, and significant predictors were financial hardship, BAP, adult attachment anxiety, degree of social support and parenting experience. Finally, psychological inflexibility (step 5) made a significant contribution to the model, explaining an additional $5.76 \%$ of the variation in anxiety. In the final model, the greatest predictors for anxiety were psychological inflexibility $(\mathrm{p}<0.0001)$, financial hardship $(p=0.0044), \operatorname{BAP}(p=0.0074)$ and parenting experience $(p=0.0250)$, which accounted for $5.76 \%, 2.38 \%, 2.10 \%$ and $1.46 \%$ of unique variance in anxiety, respectively.

In the model predicting stress, step 1 (demographic variables) did not make a significant contribution to the model (4.14\%). The only significant individual predictor was financial hardship. Step 2 (BAP) made a significant contribution to the model, explaining $9.49 \%$ of the variation in stress. Financial hardship and BAP made significant contributions to the model. The attachment variables (step 3) explained an additional $11.17 \%$ of the variation in stress, which was a significant improvement to the model. BAP and adult anxious attachment made significant contributions to the model. Parenting experience and support variables (step 4) made a significant contribution to the model, explaining an additional $7.71 \%$ of the variation in stress. Maternal education, BAP, adult attachment anxiety and parenting experience all made significant contributions to the model. Finally, psychological inflexibility (step 5) made a significant contribution to the model, explaining an additional $16.26 \%$ of the variation in stress. In the final model, the greatest predictors of stress were psychological inflexibility $(\mathrm{p}<0.0001)$, parenting experience $(\mathrm{p}=0.0020)$ and younger maternal age $(p=0.0365)$, which accounted for $16.26 \%, 2.34 \%$ and $1.06 \%$ of the variation in stress, respectively. 
MATERNAL MENTAL HEALTH AND ASD

Table 3

Hierarchical Multiple Regression Analysis Predicting Depression

\begin{tabular}{|c|c|c|c|c|c|c|c|c|c|c|c|c|c|c|c|}
\hline \multirow[b]{2}{*}{ Variable } & \multicolumn{3}{|c|}{ Model 1} & \multicolumn{3}{|c|}{ Model 2} & \multicolumn{3}{|c|}{ Model 3} & \multicolumn{3}{|c|}{ Model 4} & \multicolumn{3}{|c|}{ Model 5} \\
\hline & $\beta$ & $95 \% \mathrm{CI}$ & $s r^{2}$ & $\beta$ & $95 \% \mathrm{CI}$ & $s r^{2}$ & $\beta$ & $95 \% \mathrm{CI}$ & $s r^{2}$ & $\beta$ & $95 \% \mathrm{CI}$ & $s r^{2}$ & $\beta$ & $95 \% \mathrm{CI}$ & $s r^{2}$ \\
\hline \multicolumn{16}{|l|}{ Step 1: Demographics } \\
\hline Mother age & -0.01 & $-0.13,0.11$ & 0.00 & -0.001 & $-0.11,0.11$ & 0.000 & -0.02 & $-0.12,0.09$ & 0.000 & -0.01 & $-0.11,0.09$ & 0.000 & -0.03 & $-0.12,0.06$ & 0.001 \\
\hline Child age & -0.07 & $-0.44,0.14$ & 0.004 & -0.04 & $-0.37,0.18$ & 0.002 & -0.03 & $-0.31,0.20$ & 0.001 & 0.02 & $-0.21,0.29$ & 0.000 & 0.004 & $-0.21,0.22$ & 0.000 \\
\hline Mother education & -0.06 & $-1.87,0.73$ & 0.003 & -0.004 & $-1.29,1.22$ & 0.000 & 0.01 & $-1.05,1.28$ & 0.000 & 0.03 & $-0.80,1.41$ & 0.001 & -0.01 & $1.01,0.90$ & 0.000 \\
\hline Financial hardship & $0.29^{* * *}$ & $1.53,4.11$ & 0.075 & $0.32^{* * *}$ & $1.89,4.37$ & 0.092 & $0.20^{* *}$ & $0.79,3.18$ & 0.034 & $0.16^{* *}$ & $0.42,2.73$ & 0.020 & $0.14^{* *}$ & $0.40,2.39$ & 0.016 \\
\hline \multicolumn{16}{|l|}{ Step 2: BAP } \\
\hline BAP & & & & $0.30^{* * *}$ & $1.00,2.39$ & 0.086 & $0.17^{* *}$ & $0.26,1.62$ & 0.023 & $0.16^{* *}$ & $0.23,1.52$ & 0.020 & 0.03 & $-0.43,0.73$ & 0.001 \\
\hline \multicolumn{16}{|c|}{ Step 3: Attachment variables } \\
\hline Attachment anxiety & & & & & & & $0.31^{* * *}$ & $0.58,1.71$ & 0.050 & $0.25^{* *}$ & $0.38,1.46$ & 0.031 & 0.06 & $-0.27,0.72$ & 0.002 \\
\hline Attachment avoidance & & & & & & & 0.13 & $-0.07,1.01$ & 0.009 & 0.02 & $-0.45,0.63$ & 0.000 & 0.02 & $-0.39,0.54$ & 0.000 \\
\hline \multicolumn{16}{|c|}{ Step 4: Family and support variables } \\
\hline Parenting experience & & & & & & & & & & $0.21^{* *}$ & $0.02,0.08$ & 0.030 & $0.12^{*}$ & $0.00,0.05$ & 0.010 \\
\hline Social support & & & & & & & & & & $-0.18^{* *}$ & $-1.15,-0.20$ & 0.022 & -0.11 & $-0.83,0.01$ & 0.008 \\
\hline \multicolumn{16}{|l|}{ Step 5: Mental Health } \\
\hline $\begin{array}{l}\text { Psychological } \\
\text { inflexibility }\end{array}$ & & & & & & & & & & & & & $0.52^{* * *}$ & $0.21,0.34$ & 0.156 \\
\hline$R^{2}$ & & .10 & & & 0.19 & & & 0.32 & & & 0.39 & & & 0.55 & \\
\hline$\Delta F$ & & $6.18^{* * *}$ & & & $23.39^{* * *}$ & & & $20.67^{* * *}$ & & & $13.73^{* * *}$ & & & $74.56^{* * *}$ & \\
\hline
\end{tabular}

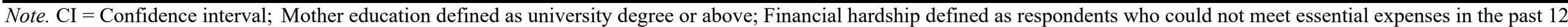
months; BAP: Broad Autism Phenotype measured using the BAPQ: Broad Autism Phenotype Questionnaire; adult attachment measured using the ECR-Q: Experiences in Close

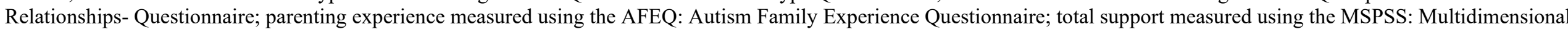
Scale of Perceived Social Support; psychological inflexibility measured using the AAQ: Acceptance and Action Questionnaire

${ }^{*} p<.05 .{ }^{* *} p<.01 .{ }^{* * *} p<.001$. 
Table 4

Hierarchical Multiple Regression Analysis Predicting Anxiety

\begin{tabular}{|c|c|c|c|c|c|c|c|c|c|c|c|c|c|c|c|}
\hline \multirow[b]{2}{*}{ Variable } & \multicolumn{3}{|c|}{ Model 1} & \multicolumn{3}{|c|}{ Model 2} & \multicolumn{3}{|c|}{ Model 3} & \multicolumn{3}{|c|}{ Model 4} & \multicolumn{3}{|c|}{ Model 5} \\
\hline & $\beta$ & $95 \% \mathrm{CI}$ & $s r^{2}$ & $\beta$ & $95 \% \mathrm{CI}$ & $s r^{2}$ & $\beta$ & $95 \% \mathrm{CI}$ & $s r^{2}$ & $\beta$ & $95 \% \mathrm{CI}$ & $s r^{2}$ & $\beta$ & $95 \% \mathrm{CI}$ & $s r^{2}$ \\
\hline \multicolumn{16}{|l|}{ Step 1: Demographics } \\
\hline Mother age & -0.06 & $-0.16,0.06$ & 0.003 & -0.05 & $-0.14,0.06$ & 0.002 & -0.06 & $-0.15,0.05$ & 0.003 & -0.05 & $-0.14,0.05$ & 0.002 & -0.07 & $-0.14,0.04$ & 0.004 \\
\hline Child age & -0.06 & $-0.38,0.15$ & 0.003 & -0.03 & $-0.31,0.18$ & 0.001 & -0.02 & $-0.28,0.21$ & 0.000 & 0.02 & $-0.19,0.28$ & 0.001 & 0.01 & $-0.20,0.26$ & 0.000 \\
\hline Mother education & -0.08 & $-1.92,0.43$ & 0.006 & -0.02 & $-1.33,0.92$ & 0.001 & -0.02 & $-1.24,0.94$ & 0.000 & 0.00 & $-1.05,1.06$ & 0.000 & -0.02 & $-1.21,0.82$ & 0.000 \\
\hline Financial hardship & $0.27^{* * *}$ & $1.20,3.55$ & 0.065 & $0.30^{* * *}$ & $1.58,3.80$ & 0.082 & $0.23^{* *}$ & $0.88,3.13$ & 0.042 & $0.19^{* *}$ & $0.54,2.75$ & 0.027 & $0.17^{* *}$ & $0.49,2.61$ & 0.024 \\
\hline \multicolumn{16}{|l|}{ Step 2: BAP } \\
\hline BAP & & & & $0.34^{* * *}$ & $1.11,2.34$ & 0.109 & $0.25^{* * *}$ & $0.66,1.94$ & 0.054 & $0.24^{* * *}$ & $0.63,1.86$ & 0.050 & $0.17^{* *}$ & $0.23,1.46$ & 0.021 \\
\hline \multicolumn{16}{|c|}{ Step 3: Attachment variables } \\
\hline Attachment anxiety & & & & & & & $0.24^{* *}$ & $0.28,1.35$ & 0.031 & $0.19^{*}$ & $0.12,1.16$ & 0.018 & 0.08 & $-0.27,0.78$ & 0.003 \\
\hline Attachment avoidance & & & & & & & 0.03 & $-0.42,0.60$ & 0.001 & -0.06 & $-0.71,0.33$ & 0.002 & -0.06 & $-0.69,0.30$ & 0.002 \\
\hline \multicolumn{16}{|c|}{ Step 4: Family and support variables } \\
\hline Parenting experience & & & & & & & & & & $0.20^{* *}$ & $0.01,0.07$ & 0.029 & $0.15^{*}$ & $0.00,0.06$ & 0.015 \\
\hline Social support & & & & & & & & & & $-0.14^{*}$ & $-0.92,-0.01$ & 0.012 & -0.09 & $-0.76,0.13$ & 0.006 \\
\hline \multicolumn{16}{|l|}{ Step 5: Mental Health } \\
\hline Psychological & & & & & & & & & & & & & $0.32^{* * *}$ & $0.09,0.22$ & 0.058 \\
\hline $\begin{array}{l}\text { intlexibility } \\
R^{2}\end{array}$ & & $0.101^{* * *}$ & & & $0.210^{* * *}$ & & & $0.265^{* * *}$ & & & $0.325^{* * *}$ & & & $0.382^{* * *}$ & \\
\hline$\Delta F$ & & 6.24 & & & 30.33 & & & 8.19 & & & 9.48 & & & 20.06 & \\
\hline
\end{tabular}

months; BAP: Broad Autism Phenotype measured using the BAPQ: Broad Autism Phenotype Questionnaire; adult attachment measured using the ECR-Q: Experiences in Close

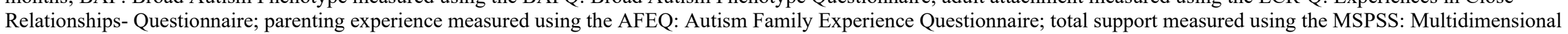

Scale of Perceived Social Support; Psychological inflexibility measured using the AAQ: Acceptance and Action Questionnaire

$* p<.05 . * * p<.01 . * * * p<.001$. 
MATERNAL MENTAL HEALTH AND ASD

Table 5

Hierarchical Multiple Regression Analysis Predicting Stress

\begin{tabular}{|c|c|c|c|c|c|c|c|c|c|c|c|c|c|c|c|}
\hline \multirow[b]{2}{*}{ Variable } & \multicolumn{3}{|c|}{ Model 1} & \multicolumn{3}{|c|}{ Model 2} & \multicolumn{3}{|c|}{ Model 3} & \multicolumn{3}{|c|}{ Model 4} & \multicolumn{3}{|c|}{ Model 5} \\
\hline & $\beta$ & $95 \% \mathrm{CI}$ & $s r^{2}$ & $\beta$ & $95 \% \mathrm{CI}$ & $s r^{2}$ & $\beta$ & $95 \% \mathrm{CI}$ & $s r^{2}$ & $\beta$ & $95 \% \mathrm{CI}$ & $s r^{2}$ & $\beta$ & $95 \% \mathrm{CI}$ & $s r^{2}$ \\
\hline \multicolumn{16}{|l|}{ Step 1: Demographics } \\
\hline Mother age & -0.09 & $-0.19,0.04$ & 0.007 & -0.08 & $-0.18,0.04$ & 0.006 & -0.10 & $-0.19,0.02$ & 0.009 & -0.09 & $-0.17,0.03$ & 0.007 & $-0.11^{*}$ & $-0.18,-0.01$ & 0.011 \\
\hline Child age & -0.08 & $-0.44,0.12$ & 0.005 & -0.05 & $-0.38,0.16$ & 0.003 & -0.04 & $-0.33,0.18$ & 0.001 & 0.02 & $-0.21,0.29$ & 0.000 & 0.00 & $-0.21,0.22$ & 0.000 \\
\hline Mother education & 0.05 & $-0.84,1.69$ & 0.002 & 0.11 & $-0.27,2.17$ & 0.009 & 0.12 & $-0.07,2.23$ & 0.012 & $0.14^{*}$ & $0.15,2.35$ & 0.016 & 0.10 & $-0.06,1.86$ & 0.008 \\
\hline Financial hardship & $0.16^{*}$ & $0.27,2.79$ & 0.025 & $0.20^{* *}$ & $0.63,3.04$ & 0.035 & 0.09 & $-0.36,2.01$ & 0.007 & 0.04 & $-0.82,1.48$ & 0.001 & 0.02 & $-0.85,1.16$ & 0.000 \\
\hline \multicolumn{16}{|l|}{ Step 2: BAP } \\
\hline BAP & & & & $0.32^{* * *}$ & $1.01,2.35$ & 0.095 & $0.19^{* *}$ & $0.35,1.69$ & 0.031 & $0.18^{* *}$ & $0.31,1.59$ & 0.027 & 0.05 & $-0.33,0.84$ & 0.002 \\
\hline \multicolumn{16}{|c|}{ Step 3: Attachment variables } \\
\hline Attachment anxiety & & & & & & & $0.30^{* * *}$ & $0.48,1.59$ & 0.046 & $0.24^{* *}$ & $0.29,1.37$ & 0.029 & 0.05 & $-0.33,0.66$ & 0.001 \\
\hline Attachment avoidance & & & & & & & 0.11 & $-0.17,0.90$ & 0.006 & 0.03 & $-0.44,0.64$ & 0.000 & 0.03 & $-0.38,0.56$ & 0.000 \\
\hline \multicolumn{16}{|c|}{ Step 4: Family and support variables } \\
\hline Parenting experience & & & & & & & & & & $0.28^{* * *}$ & $0.03,0.09$ & 0.054 & $0.19^{* *}$ & $0.02,0.06$ & 0.023 \\
\hline Social support & & & & & & & & & & -0.08 & $-0.77,0.18$ & 0.005 & -0.01 & $-0.46,0.38$ & 0.000 \\
\hline \multicolumn{16}{|l|}{ Step 5: Mental Health } \\
\hline $\begin{array}{l}\text { Psychological } \\
\text { inflexibility }\end{array}$ & & & & & & & & & & & & & $0.53^{* * *}$ & $0.20,0.33$ & 0.163 \\
\hline$R^{2}$ & & 0.041 & & & $0.136^{* * *}$ & & & $0.248^{* * *}$ & & & $0.325^{* * *}$ & & & $0.488^{* * *}$ & \\
\hline$\Delta F$ & & 2.39 & & & 24.18 & & & 16.19 & & & 12.33 & & & 68.23 & \\
\hline
\end{tabular}

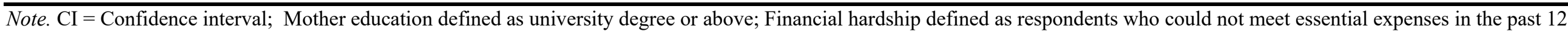
months; BAP: Broad Autism Phenotype measured using the BAPQ: Broad Autism Phenotype Questionnaire; adult attachment measured using the ECR-Q: Experiences in Close

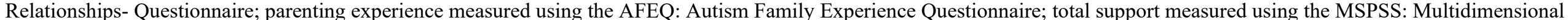
Scale of Perceived Social Support; Psychological inflexibility measured using the AAQ: Acceptance and Action Questionnaire ${ }^{*} p<.05$. **p $<.01$. ***p $<.001$. 


\section{Mediation Analysis}

Multiple mediation analyses were conducted using bootstrapping to test whether parenting experience, psychological inflexibility, support, and/or adult attachment mediated the relationships between BAP and maternal mental health. Data screening was conducted according to the steps outlined by Tabachnick and Fidell (2013). Outliers were excluded if they had values above the cut-off score for two or more of the following: Mahalanobis cut-off score of $22.46(\mathrm{p}<0.001)$, Cooks Distance and Leverage values analysis. Two outliers were removed from the mediation analyses predicting depressive symptoms and stress. One outlier was removed from the analysis predicting anxiety. The assumptions of additivity, normality, linearity and homoscedasticity were met.

Figure 1 shows results of the mediation analyses. There was a significant total mediation effect for the relationship between BAP and depressive symptoms (Indirect Effect $=1.58, \mathrm{SE}=0.30,95 \% \mathrm{CI}[1.01,2.18])$ with psychological flexibility (Indirect Effect $=1.10, \mathrm{SE}=0.24,95 \% \mathrm{CI}[0.66,1.61])$ and parenting experience (Indirect Effect $=0.14$, $\mathrm{SE}=0.08,95 \% \mathrm{CI}[0.01,0.32])$ both individually mediating this relationship. Likewise, there was a total mediation effect for the relationship between BAP and anxiety (Indirect Effect $=0.99, \mathrm{SE}=0.23,95 \% \mathrm{CI}[0.58,1.46])$, with psychological inflexibility (Indirect Effect $=0.65, \mathrm{SE}=0.19,95 \% \mathrm{CI}[0.31,1.05])$ and parenting experience (Indirect Effect $=0.14$, $\mathrm{SE}=0.09,95 \% \mathrm{CI}[0.01,0.34])$ again individually mediating this relationship. Lastly, there was a significant total mediation effect for the relationship between BAP and stress (Indirect Effect $=1.42, \mathrm{SE}=0.27,95 \% \mathrm{CI}[0.91,1.98])$ with psychological inflexibility alone (Indirect Effect $=1.16, \mathrm{SE}=0.23,95 \% \mathrm{CI}[0.75,1.65])$ individually mediating this relationship. 


\section{Figure 1A-C.}

Multiple mediation analysis of the direct effect of BAP on maternal mental health for the mediators psychological inflexibility and parenting experience.
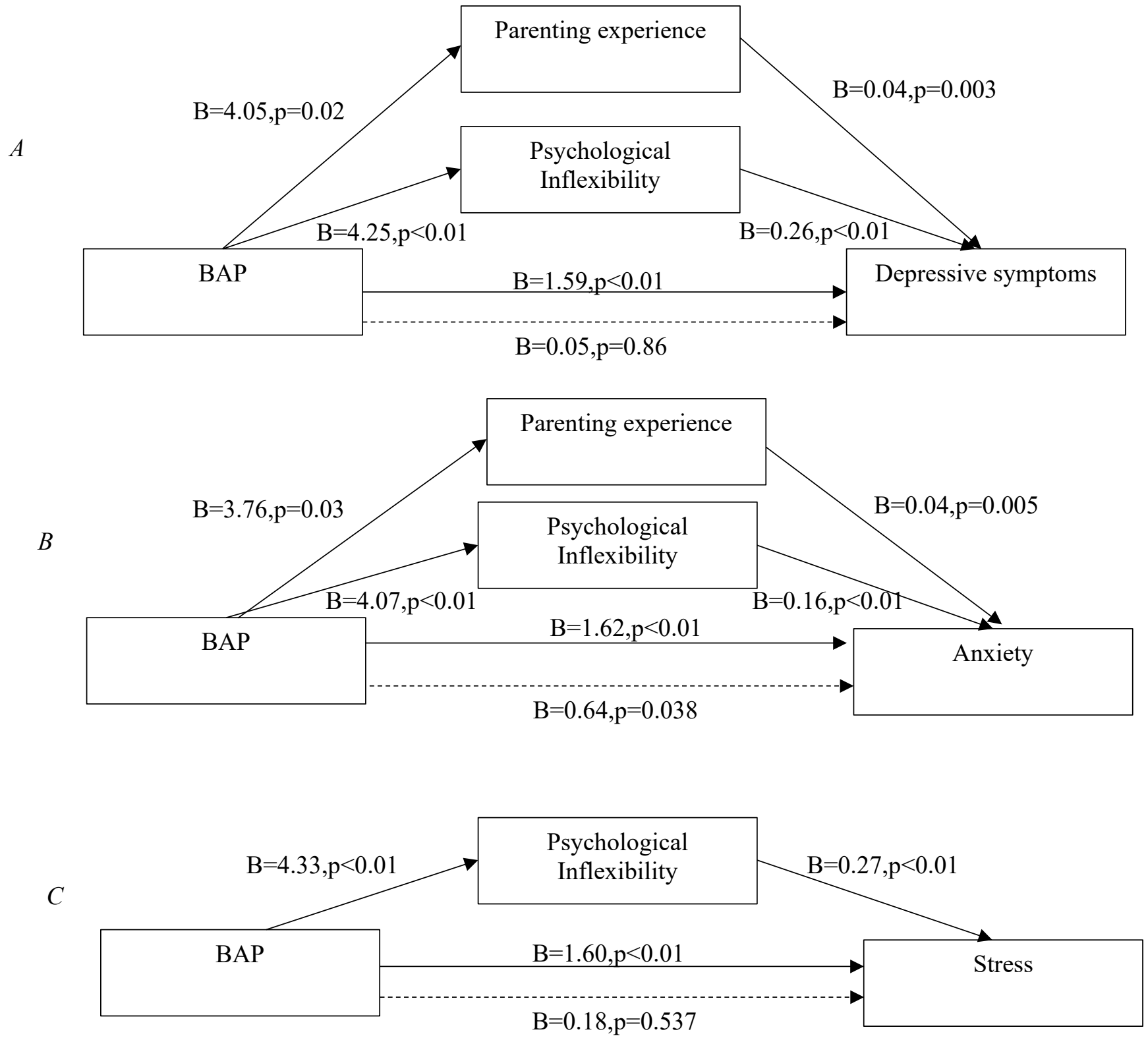

Note. Figures represent unstandardised regression coefficients. Dashed arrows represent direct effects after controlling for mediator variables 


\section{Discussion}

This study explored the predictors of poor mental health in mothers of young children with ASD and revealed that psychological inflexibility and challenging parenting experiences were the greatest predictors of depressive symptoms, anxiety and stress above and beyond the effects of demographics, attachment, family support and the BAP.

Psychological inflexibility and challenging parenting experiences were the strongest predictors of depressive symptoms of mothers of children with ASD. This is in agreement with previous literature examining the mental health mothers of children with chronic health and developmental diagnoses including autism (Sairanen et al., 2018). However, unlike previous literature which showed that social support mediated the relationship between BAP and maternal mental health (Ingersoll \& Hambrick, 2011; Pruitt et al., 2016), our data revealed that psychological inflexibility and challenging parenting experiences were more important mediators of the relationship between BAP and depressive symptoms.

Similar results were found for models predicting anxious symptoms, with psychological inflexibility emerging as the greatest predictor of anxious symptomatology. Challenging parenting experiences also predicted anxiety in mothers of children with ASD, which is congruent with previous findings that children's core ASD symptoms (Zhou et al., 2019) and behavioural problems and parental self-efficacy (Hastings \& Brown, 2002) are all associated with anxiety in mothers of children with ASD. Results further showed that psychological inflexibility and challenging parenting experiences partially mediated the relationship between BAP and anxiety in mothers of children with ASD, extending previous findings (Lau et al., 2014).

BAP was also found to predict anxiety in a manner not accounted for by psychological flexibility alone, following addition of all variables to the regression model. While psychological inflexibility and parenting challenges mediated the relationship between 
the BAP and anxiety, this relationship was not fully explained by the mediation model. This highlights the importance of identifying other pathways, such as greater likelihood of having a history of negative social experiences, that may lead to increased anxious traits in people with the BAP. Finally, maternal anxiety was also predicted by financial hardship which is in line with previous literature regarding the health-related effects of financial stressors (Carlisle et al., 2017).

Similar to depressive symptoms and anxiety and as corroborated by previous research (Sairanen et al., 2018), maternal stress was also predicted by psychological inflexibility. Another important contributor to maternal stress was challenging parenting experiences, which predicted maternal stress. This is in line with a longitudinal research with parents of children with ASD which found that children's symptom severity (a factor that can contribute to parenting experience) increased parental stress, which, in turn, increased parental depression (Benson \& Karlof, 2009). Further, younger maternal age predicted stress in our sample; however, the link between parental age and stress is unclear in previous literature. Although one study found that older mothers may experience more difficulties responding to the challenges of raising a child with ASD (Rezendes \& Scarpa, 2011), another found younger parental age to be linked with poorer mental health (Falk et al., 2014). In the present study, younger maternal age was associated with lower education levels, which could contribute to increased stress as found in previous research with parents of children with ASD (Krakovich et al., 2016).

Overall, our results revealed that psychological inflexibility was the greatest predictor of poor maternal mental health in mothers of children with ASD and was associated with BAP traits. The exact nature of the relationship between BAP and psychological inflexibility remains to be explored. However, the concepts clearly have overlapping features and were moderately correlated in this study. Both involve behavioural rigidity, cognitive inflexibility 
(Gokcen et al., 2014; Hayes et al., 2003; Hayes et al., 2011), difficulties with flexible perspective taking (Baron-Cohen, 2004; Whittingham \& Coyne, 2019) and the dominance of literal understandings of language (Hayes et al., 2011; Piven et al., 1997), which could contribute to adverse mental health outcomes. However, while these similarities exist, the BAP is considered a neurological difference that would be expected to persist across an individual's lifespan while psychological inflexibility is a skill that can be changed and varies according to context.

By targeting psychological inflexibility, the mental health of mothers of children may be improved, which has the potential to improve maternal and family well-being as well as have flow on effects to improve the parenting experience, parental confidence and child developmental outcomes (Bernard-Bonnin et al., 2004; Brown, Whittingham, \& Sofronoff, 2015; Leeming \& Hayes, 2016). These findings suggest that maternal mental health could be supported by targeting psychological inflexibility. Acceptance and Commitment Therapy (ACT) is a cognitive behavioural therapy focussing on enhancing psychological flexibility. ACT has been efficacious in improving depressive symptoms, general distress and stress in mothers of children with ASD (Blackledge \& Hayes, 2006; Joekar et al., 2016; Lunsky et al., 2018). Despite promising results, previous studies have been limited by quasi-experimental uncontrolled trial designs; in order to establish the efficacy of supporting mothers of children with ASD through ACT, high-quality randomised controlled trials are required. As psychological flexibility includes mindfulness, these results also point towards the potential usefulness of mindfulness-based interventions, which have previously been shown to improve the mental health of mothers of children with ASD (Dykens et al., 2014; Ferraioli \& Harris, 2013; Hastings \& Manikam, 2013)

The present study also found that parenting experience mediated the relationship between BAP and depression and anxiety, suggesting that greater BAP scores were 
associated with challenging parenting experiences, possibly due to increased child autism severity (Sasson, Lam, Parlier, et al., 2013) and/or parental executive functioning deficits (Hughes et al., 1997), which can contribute to difficulties in parenting, lower parenting confidence and poorer parental self-efficacy. The link between the BAP, parenting experience and mental health outcomes emphasises the need to provide parenting support that takes into account parental BAP, for example by tailoring the strategies or examples used in intervention sessions as needed.

A major strength of this study was that almost half of the sample (42.6\%) scored above BAP cut-off scores (Sasson, Lam, Childress, et al., 2013), indicating elevated BAP traits. This is higher than previous reports of the BAP measured by the BAPQ, which ranged from $2.6 \%$ to $40.0 \%$ in mothers of children with ASD (Rubenstein \& Chawla, 2018). Although our study focused on mothers, exploring the experiences of fathers of children with ASD could bring fresh insights, particularly in relation to BAP as it is more prevalent in fathers when compared to mothers of children with ASD (Rubenstein \& Chawla, 2018). The current sample was also representative of the broader population of Australian mothers in terms of education level and marital status ; however, a relatively smaller proportion of mothers in this sample experienced financial distress when compared to the broader population, potentially limiting the generalisability of the results (Australian Bureau of Statistics, 2020). Our study relied on a self-report of assessment BAP, whereas the measure was designed to be an average of self- and informant-report. A previous study found no significant difference between informant- and self-report scores; however, the informantreport scores had higher sensitivity and specificity (Hurley et al., 2007). It was also not possible to confirm children's ASD diagnoses due to the anonymous online nature of the study. Further, the regression models did not include a discrete measure of children's symptom severity, which has previously been found to be associated with maternal mental 
health (Benson, 2006; Benson \& Karlof, 2009; Miranda et al., 2019; Zhou et al., 2019). Lastly, the cross-sectional design of this study precludes the inference of causal relationships as a longitudinal design is required to ascertain directionality and causation (Setia, 2016).

\section{Conclusion}

Psychological inflexibility and challenging parenting experiences were important predictors of maternal mental health and mediated the relationship between BAP and mental health. The mechanisms underlying the relationship between BAP and psychological inflexibility and the relationship between BAP and challenging parenting experiences needs to be further elucidated in order to inform intervention development. However, this study indicates that interventions that focus on improving psychological flexibility while supporting parenting could assist in better supporting mental health in mothers of young children with ASD. 


\section{References}

Alvarez, S. L., Meltzer-Brody, S., Mandel, M., \& Beeber, L. (2015). Maternal Depression and Early Intervention: A Call for an Integration of Services. Infants and young children, 28(1), 72-87. https://doi.org/10.1097/IYC.0000000000000024

American Psychiatric Association. (2013). Diagnostic and statistical manual of mental disorders : DSM-5 (Fifth edition.. ed.). Arlington, VA : American Psychiatric Publishing.

Australian Bureau of Statistics. (2020). 2016 Census - Employment, Income and Education

Baron-Cohen, S. (2004). The cognitive neuroscience of autism. Journal of neurology, $\begin{array}{llr}\text { neurosurgery, } \quad \text { and } & \text { 75ychiatry, }\end{array}$ https://doi.org/10.1136/jnnp.2003.018713

Benson, P. (2006). The Impact of Child Symptom Severity on Depressed Mood Among Parents of Children with ASD: The Mediating Role of Stress Proliferation. J Autism Dev Disord, 36, 685-695. https://doi.org/10.1007/s10803-006-0112-3

Benson, P. R., \& Karlof, K. L. (2009). Anger, Stress Proliferation, and Depressed Mood Among Parents of Children with ASD: A Longitudinal Replication. J Autism Dev Disord, 39(2), 350-362. https://doi.org/10.1007/s10803-008-0632-0

Bernard-Bonnin, A.-C., Society, C. P., Health, M., \& Committee, D. D. (2004). Maternal depression and child development. Paediatrics \& child health, 9(8), 575-583. https://doi.org/10.1093/pch/9.8.575

Bitsika, V., Sharpley, C. F., \& Bell, R. (2013). The Buffering Effect of Resilience upon Stress, Anxiety and Depression in Parents of a Child with an Autism Spectrum Disorder. Journal of Developmental and Physical Disabilities, 25(5), 533-543. https://doi.org/10.1007/s10882-013-9333-5 
Blackledge, J. T., \& Hayes, S. C. (2006). Using Acceptance and Commitment Training in the Support of Parents of Children Diagnosed with Autism. Child \& Family Behavior Therapy, 28(1), 1-18. https://doi.org/10.1300/J019v28n01_01

Bond, F. W., Hayes, S. C., Baer, R. A., Carpenter, K. M., Guenole, N., Orcutt, H. K., Waltz, T., \& Zettle, R. D. (2011). Preliminary psychometric properties of the Acceptance and Action Questionnaire-II: a revised measure of psychological inflexibility and experiential avoidance. Behavior therapy, 42(4), 676-688. https://doi.org/10.1016/j.beth.2011.03.007

Boyd, B. A. (2002). Examining the Relationship BetWeen Stress and Lack of Social Support in Mothers of Children With Autism. Focus on Autism and Other Developmental Disabilities, 17(4), 208-215. https://doi.org/10.1177/10883576020170040301

Brown, F. L., Whittingham, K., Boyd, R. N., McKinlay, L., \& Sofronoff, K. (2015). Does Stepping Stones Triple P plus Acceptance and Commitment Therapy improve parent, couple, and family adjustment following paediatric acquired brain injury? A randomised controlled trial. Behaviour research and therapy, 73, 58-66. https://doi.org/https://doi.org/10.1016/j.brat.2015.07.001

Brown, F. L., Whittingham, K., \& Sofronoff, K. (2015). Parental experiential avoidance as a potential mechanism of change in a parenting intervention for parents of children with pediatric acquired brain injury. $J$ Pediatr Psychol, 40(4), 464-474. https://doi.org/10.1093/jpepsy/jsu109

Cantazaro, A., \& Wei, M. (2010). Adult Attachment, Dependence, Self-Criticism, and Depressive Symptoms: A Test of a Mediational Model. Journal of Personality, 78(4), 1135-1162. https://doi.org/10.1111/j.1467-6494.2010.00645.x 
Cappadocia, M. C., Weiss, J. A., \& Pepler, D. (2012). Bullying Experiences Among Children and Youth with Autism Spectrum Disorders. J Autism Dev Disord, 42(2), 266-277. https://doi.org/10.1007/s10803-011-1241-x

Carlisle, K., Larkins, S., \& Croker, F. (2017). Disparities in dental health of rural Australians: hospitalisation rates and utilisation of public dental services in three communities in North Queensland. Rural Remote Health, 17(1), 3807. https://doi.org/10.22605/rrh3807

Cernvall, M., Skogseid, E., Carlbring, P., Ljungman, L., Ljungman, G., \& von Essen, L. (2016). Experiential Avoidance and Rumination in Parents of Children on Cancer Treatment: Relationships with Posttraumatic Stress Symptoms and Symptoms of Depression. Journal of Clinical Psychology in Medical Settings, 23(1), 67-76. https://doi.org/10.1007/s10880-015-9437-4

Dykens, E. M., Fisher, M. H., Taylor, J. L., Lambert, W., \& Miodrag, N. (2014). Reducing distress in mothers of children with autism and other disabilities: a randomized trial. Pediatrics, 134(2), e454-e463. https://doi.org/10.1542/peds.2013-3164

Evans, T., Whittingham, K., \& Boyd, R. (2012). What helps the mother of a preterm infant become securely attached, responsive and well-adjusted? Infant Behavior and Development, 35(1), 1-11. https://doi.org/https://doi.org/10.1016/j.infbeh.2011.10.002

Falk, N. H., Norris, K., \& Quinn, M. G. (2014). The factors predicting stress, anxiety and depression in the parents of children with autism. J Autism Dev Disord, 44(12), 31853203.

Ferraioli, S. J., \& Harris, S. L. (2013). Comparative Effects of Mindfulness and Skills-Based Parent Training Programs for Parents of Children with Autism: Feasibility and Preliminary Outcome Data. Mindfulness, 4(2), 89-101. https://doi.org/10.1007/s12671012-0099-0 
Fraley, R. C., Waller, N. G., \& Brennan, K. A. (2000). An item response theory analysis of self-report measures of adult attachment. Journal of Personality and Social Psychology, 78(2), 350-365. https://doi.org/10.1037/0022-3514.78.2.350

Gokcen, E., Petrides, K. V., Hudry, K., Frederickson, N., \& Smillie, L. D. (2014). Subthreshold autism traits: the role of trait emotional intelligence and cognitive flexibility. Br J Psychol, 105(2), 187-199. https://doi.org/10.1111/bjop.12033

Hastings, R. P., \& Brown, T. (2002). Behavior Problems of Children With Autism, Parental Self-Efficacy, and Mental Health. American Journal on Mental Retardation, 107(3), 222-232. https://doi.org/10.1352/0895-8017(2002)107<0222:Bpocwa $>2.0 . C 0 ; 2$

Hastings, R. P., \& Manikam, R. (2013). Mindfulness and Acceptance in Developmental Disabilities: Introduction to the Special Issue. Mindfulness, 4(2), 85-88. https://doi.org/10.1007/s12671-013-0207-9

Hayes, S. C., Strosahl, K., \& Wilson, K. G. (2003). Acceptance and commitment therapy an experiential approach to behavior change. Guilford Press.

Hayes, S. C., Strosahl, K. D., \& Wilson, K. G. (2011). Acceptance and Commitment Therapy, Second Edition: The Process and Practice of Mindful Change. Guilford Publications. https://books.google.com.au/books?id=og28CwAAQBAJ

Hughes, C., Leboyer, M., \& Bouvard, M. (1997). Executive function in parents of children with autism. Psychological Medicine, 27(1), 209-220. https://doi.org/10.1017/S0033291796004308

Hurley, R. S., Losh, M., Parlier, M., Reznick, J. S., \& Piven, J. (2007). The broad autism phenotype questionnaire. $J$ Autism Dev Disord, 37(9), 1679-1690. https://doi.org/10.1007/s10803-006-0299-3

Ingersoll, B., \& Hambrick, D. Z. (2011). The relationship between the broader autism phenotype, child severity, and stress and depression in parents of children with autism 
spectrum disorders. Research in Autism Spectrum Disorders, 5(1), 337-344. https://doi.org/https://doi.org/10.1016/j.rasd.2010.04.017

Ingersoll, B., Meyer, K., \& Becker, M. W. (2011). Increased rates of depressed mood in mothers of children with ASD associated with the presence of the broader autism phenotype. Autism Research, 4(2), 143-148. https://doi.org/10.1002/aur.170

Joekar, S., Farid, A. A., Nirashk, B., Gharraee, B., \& Mohammadian, M. (2016). Effectiveness of Acceptance and Commitment Therapy in the support of parents of children with high-functioning Autism. International Journal of Humanities and Cultural Studies, 2(4).

Keenan, B. M., Newman, L. K., Gray, K. M., \& Rinehart, N. J. (2016). Parents of Children with ASD Experience More Psychological Distress, Parenting Stress, and AttachmentRelated Anxiety. J Autism Dev Disord, 46(9), 2979-2991. https://doi.org/10.1007/s10803-016-2836-z

Krakovich, T. M., McGrew, J. H., Yu, Y., \& Ruble, L. A. (2016). Stress in Parents of Children with Autism Spectrum Disorder: An Exploration of Demands and Resources. J Autism Dev Disord, 46(6), 2042-2053. https://doi.org/10.1007/s10803-016-2728-2

Lamport, D., \& Turner, L. A. (2014). Romantic Attachment, Empathy, and the Broader Autism Phenotype among College Students. The Journal of Genetic Psychology, 175(3), 202213. https://doi.org/10.1080/00221325.2013.856838

Lau, W. Y.-P., Gau, S. S.-F., Chiu, Y.-N., \& Wu, Y.-Y. (2014). Autistic Traits in Couple Dyads as a Predictor of Anxiety Spectrum Symptoms. J Autism Dev Disord, 44(11), 29492963. https://doi.org/10.1007/s10803-014-2151-5

Leadbitter, K., Aldred, C., McConachie, H., Le Couteur, A., Kapadia, D., Charman, T., Macdonald, W., Salomone, E., Emsley, R., Green, J., \& Consortium, P. (2018). The Autism Family Experience Questionnaire (AFEQ): An Ecologically-Valid, Parent- 
Nominated Measure of Family Experience, Quality of Life and Prioritised Outcomes for Early Intervention. $J$ Autism Dev Disord, 48(4), 1052-1062. https://doi.org/10.1007/s10803-017-3350-7

Ledley, D. R., Storch, E. A., Coles, M. E., Heimberg, R. G., Moser, J., \& Bravata, E. A. (2006). The Relationship Between Childhood Teasing and Later Interpersonal Functioning. Journal of Psychopathology and Behavioral Assessment, 28(1), 33-40. https://doi.org/10.1007/s10862-006-4539-9

Leeming, E., \& Hayes, S. C. (2016). Parents Are People Too: The Importance of Parental Psychological Flexibility. Clinical Psychology: Science and Practice, 23(2), 158-160. https://doi.org/10.1111/cpsp.12147

Little, L. (2002). Middle-Class Mothers' Perceptions of Peer and Sibling Victimization among Children with Asperger's Syndrome and Learning Disorders Issues in Comprehensive Pediatric Nursing, 25(1), 43-57. https://doi.org/10.1080/014608602753504847

Lovibond, P. F., \& Lovibond, S. H. (1995). The structure of negative emotional states: Comparison of the Depression Anxiety Stress Scales (DASS) with the Beck Depression and Anxiety Inventories. Behaviour research and therapy, 33(3), 335-343.

Lunsky, Y., Fung, K., Lake, J., Steel, L., \& Bryce, K. (2018). Evaluation of Acceptance and Commitment Therapy (ACT) for Mothers of Children and Youth with Autism SpectrumDisorder. Mindfulness, 9(4), 1110-1116. https://doi.org/10.1007/s12671-0170846-3

Mackinnon, D. P., \& Fairchild, A. J. (2009). Current Directions in Mediation Analysis. Current directions in psychological science, 18(1), 16-16. https://doi.org/10.1111/j.14678721.2009.01598.x

Mak, W. W. S., Ho, A. H. Y., \& Law, R. W. (2007). Sense of Coherence, Parenting Attitudes and Stress among Mothers of Children with Autism in Hong Kong. Journal of Applied 
Research in Intellectual Disabilities, 20(2), 157-167. https://doi.org/10.1111/j.14683148.2006.00315.x

Mikulincer, M., \& Shaver, P. R. (2012). An attachment perspective on psychopathology. World psychiatry : official journal of the World Psychiatric Association (WPA), 11(1), 11-15. https://doi.org/10.1016/j.wpsyc.2012.01.003

Miranda, A., Mira, A., Berenguer, C., Rosello, B., \& Baixauli, I. (2019). Parenting Stress in Mothers of Children With Autism Without Intellectual Disability. Mediation of Behavioral Problems and Coping Strategies. Frontiers in psychology, 10, 464-464. https://doi.org/10.3389/fpsyg.2019.00464

Morawska, A., \& Sanders, M. R. (2010). Triple P tip sheet: Managing Chronic Illness.

Piven, J. (2001). The broad autism phenotype: A complementary strategy for molecular genetic studies of autism. American Journal of Medical Genetics, 105(1), 34-35. https://doi.org/10.1002/1096-8628(20010108)105:1<34::AID-AJMG1052>3.0.CO;2$\mathrm{D}$

Piven, J., \& Palmer, P. (1999). Psychiatric Disorder and the Broad Autism Phenotype: Evidence From a Family Study of Multiple-Incidence Autism Families. American Journal of Psychiatry, 156(4), 557-563. https://doi.org/10.1176/ajp.156.4.557

Piven, J., Palmer, P., Landa, R., Santangelo, S., Jacobi, D., \& Childress, D. (1997). Personality and language characteristics in parents from multiple-incidence autism families. American Journal of Medical Genetics, 74(4), 398-411. https://doi.org/10.1002/(sici)1096-8628(19970725)74:4<398::Aid-ajmg11>3.0.Co;2-d

Pohl, A. L., Crockford, S. K., Blakemore, M., Allison, C., \& Baron-Cohen, S. (2020). A comparative study of autistic and non-autistic women's experience of motherhood. Molecular Autism, 11(1), 3. https://doi.org/10.1186/s13229-019-0304-2 
Prata, J., Lawson, W., \& Coelho, R. (2019). Stress factors in parents of children on the autism spectrum: an integrative model approach. International Journal of Clinical Neurosciences and Mental Health, 2. https://doi.org/10.21035/ijcnmh.2019.6.2

Preacher, K. J., \& Hayes, A. F. (2004). SPSS and SAS procedures for estimating indirect effects in simple mediation models. Behavior Research Methods, Instruments, \& Computers, 36(4), 717-731. https://doi.org/10.3758/BF03206553

Pruitt, M. M., Rhoden, M., \& Ekas, N. V. (2016). Relationship between the broad autism phenotype, social relationships and mental health for mothers of children with autism spectrum disorder. Autism, 22(2), 171-180. https://doi.org/10.1177/1362361316669621

Rezendes, D. L., \& Scarpa, A. (2011). Associations between Parental Anxiety/Depression and Child Behavior Problems Related to Autism Spectrum Disorders: The Roles of Parenting Stress and Parenting Self-Efficacy. Autism Res Treat, 2011, 395190. https://doi.org/10.1155/2011/395190

Rosbrook, A., \& Whittingham, K. (2010). Autistic traits in the general population: What mediates the link with depressive and anxious symptomatology? Research in Autism Spectrum Disorders, $\quad 4(3), \quad 415-424$. https://doi.org/https://doi.org/10.1016/j.rasd.2009.10.012

Rubenstein, E., \& Chawla, D. (2018). Broader autism phenotype in parents of children with autism: a systematic review of percentage estimates. J Child Fam Stud, 27(6), 17051720. https://doi.org/10.1007/s10826-018-1026-3

Sairanen, E., Lappalainen, P., \& Hiltunen, A. (2018). Psychological inflexibility explains distress in parents whose children have chronic conditions. PLOS ONE, 13(7), e0201155. https://doi.org/10.1371/journal.pone.0201155

Sasson, N. J., Lam, K. S. L., Childress, D., Parlier, M., Daniels, J. L., \& Piven, J. (2013). The broad autism phenotype questionnaire: prevalence and diagnostic classification. Autism 
research : official journal of the International Society for Autism Research, 6(2), 134143. https://doi.org/10.1002/aur.1272

Sasson, N. J., Lam, K. S. L., Parlier, M., Daniels, J. L., \& Piven, J. (2013). Autism and the broad autism phenotype: familial patterns and intergenerational transmission. Journal of Neurodevelopmental Disorders, 5(1), 11. https://doi.org/10.1186/1866-1955-5-11

Setia, M. S. (2016). Methodology Series Module 3: Cross-sectional Studies. Indian journal of dermatology, 61(3), 261-264. https://doi.org/10.4103/0019-5154.182410

Tabachnick, B. G., \& Fidell, L. S. (2013). Using multivariate statistics (6th ed., New International Edition. ed.). Pearson Education Limited.

von Elm, E., Altman, D. G., Egger, M., Pocock, S. J., Gotzsche, P. C., \& Vandenbroucke, J. P. (2008). The Strengthening the Reporting of Observational Studies in Epidemiology (STROBE) statement: guidelines for reporting observational studies. J Clin Epidemiol, 61(4), 344-349. https://doi.org/10.1016/j.jclinepi.2007.11.008

Whittingham, K., \& Coyne, L. W. (2019). Acceptance and commitment therapy: the clinician's guide for supporting parents. Academic Press.

Whittingham, K., Wee, D., Sanders, M. R., \& Boyd, R. (2013). Predictors of psychological adjustment, experienced parenting burden and chronic sorrow symptoms in parents of children with cerebral palsy. Child: Care, Health and Development, 39(3), 366-373. https://doi.org/10.1111/j.1365-2214.2012.01396.x

Zhou, W., Liu, D., Xiong, X., \& Xu, H. (2019). Emotional problems in mothers of autistic children and their correlation with socioeconomic status and the children's core symptoms. $\quad$ Medicine, $\quad$ 98(32), e16794-e16794. https://doi.org/10.1097/MD.0000000000016794 
